\title{
Psychopathic traits in adolescence: A review
}

\section{Traços psicopáticos na adolescência: uma revisão}

\author{
Ramiro RONCHETTI \\ Gabriel José Chittó GAUER ${ }^{1}$ \\ Sílvio VASCONCELLOS ${ }^{2}$ \\ Leonardo Machado da SILVA ${ }^{1}$ \\ Guinter LUHRING' ${ }^{1}$ \\ Aline RUBIN ${ }^{1}$ \\ Alice MARTINES'
}

\begin{abstract}
Currently, and throughout the history of mental healthcare, the literature highlights that there is no agreement on the use of the terms "antisocial personality disorder" and "psychopathic personality". This paper aims to promote a debate over these concepts and their evaluation for both adults and adolescents. With this aim, a systematic review was conducted in the MedLine data base between 1968 and March 2011 using the terms "adolescent", "antisocial personality disorder", and "personality assessment". From the 59 identified articles 29 were selected to further analysis. The discussion of these terms was confirmed, as well as the importance of assessing psychopathic traits during adolescence. An initial tendency to disregard the term psychopathy and its affective implications was evidenced. However, the latest psychological instruments return to the discussion regarding the use of this diagnosis and its implications.
\end{abstract}

Keywords: Adolescent; Antisocial personality disorder; Psychopathy.

\section{Resumo}

Atualmente e durante a história da saúde mental, encontram-se, na literatura, diferentes posicionamentos a respeito dos termos "transtorno de personalidade antissocial" e "personalidade psicopática". Este artigo tem como objetivo debater esses conceitos em relação a sua avaliação tanto na vida adulta como na adolescência. Para tal, foi realizada uma revisão sistemática na base de dados MedLine, de 1968 a março de 2011, cruzando os descritores "adolescente", "transtorno antissocial da personalidade" e "avaliação da personalidade". A partir dos 59 artigos identificados, foram selecionados 29 para serem analisados. A discussão dos termos é encontrada no material revisado, bem como a importância de identificação de traços de psicopatia na adolescência. Evidencia-se uma tendência inicial ao abandono do termo psicopatia e as alterações afetivas relacionadas a ela. No entanto, os instrumentos de avaliação psicológica mais recentes retomam a discussão desse diagnóstico e suas implicações.

Palavras-chave: Adolescência; Tratamento da personalidade antisocial; Psicopatia.

$\checkmark v \nabla v$

1 Pontifícia Universidade Católica do Rio Grande do Sul, Faculdade de Psicologia, Programa de Pós-Graduação em Psicologia Clínica. Av. Ipiranga, 6681, Partenon, 90619-900, Porto Alegre, RS, Brasil. Correspondência para/Correspondence to: L.M. SILVA. E-mail: <leonardo.silva@pucrs.br>.

2 Universidade Federal de Santa Maria, Faculdade de Psicologia, Programa de Pós-Graduação em Psicologia em Saúde, Desenvolvimento e Contextos Sociais. Santa Maria, RS, Brasil.

Article based on the master thesis of R. RONCHETTI, intitled "Estudo de revisão e fidedignidade do Inventário de Psicopatia de Hare: versão Jovens (PCL: YV)". Pontifícia Universidade Católica do Rio Grande do Sul, 2009.

Support: Conselho Nacional de Desenvolvimento Científico e Tecnológico, no 131701/2007-0. 
Descriptions of violent and uncontrolled behaviors, as well as the mental instability of some individuals, were already part of the reports made by the earliest mental health studies, conducted by authors such as Pinel, in France, and by Benjamin Rush, in the United States, over the course of XIX century. Later the term "psychopath" became popular mainly by the virtue of two authors: David Henderson and Hervey Cleckley. David Henderson published his book Psychopathic States in 1939 defining three types of psychopaths: The predominantly inadequate (category which contemplates people who were marginalized by society), the predominantly aggressive (dangerous individuals due to their violent acts) and the creative (individuals destined to overcome any obstacle that stands in their way) (Black \& Larson 1999). However, no conceptualization or study was more relevant than that of Hervey Cleckley, developing the first comprehensive and contextualized psychopathy description in the book The Mask of Sanity (Cleckley, 1976). Reviewed four times since its publication in 1941, the book currently remains an important source of information and is considered an indispensable tool in the phenomenological comprehension of psychopathy. The author defined the disorder in similar terms to the contemporary view of psychopathy, as a category distinct from the other mental disorders and behavioral alterations. Through a succession of Clinical Case Summaries, he demonstrated how the disorder transcends social class. The current psychopathy concept, including Antisocial Personality Disorder (APD), its repercussions, and the image people currently have of a Psychopath, is based on the work of Cleckley and his emphasis of the sixteen defining traits of psychopathy (Chart 1). Since the first edition of Cleckley's book, revisions regarding the nomenclature have been made by the American Psychiatric Association. The classification of a psychopathic personality was changed to that of sociopathic personality in 1958. In 1968 it was changed again to antisocial personality, although he emphasizes in the $5^{\text {th }}$ edition the fact that the term psychopath better represents the disorder. The evolution of nomenclature and different criteria on
A series of later works were influenced by the theoretical framework of Cleckley, fundamentally because his ideas had a direct influence on the Diagnostic and Statistical Manual (DSM-I), in 1952, under the name of Antisocial Reaction. This term replaced the previous criteria of psychopathic personality and constitutional psychopathic state. The term APD was introduced in (American Psychiatric Association, 1968 [APA]) in the second edition of the DSM, which distinguished the disorder from other situations such as chemical dependence, alcoholism and deviant sexual behavior. Due to the great acceptance of this classification by the scientific community, the term was consolidated in the third edition of the DSM (APA, 1980), through a list of specific criteria that would justify the psychiatric diagnosis. The third edition of the DSM recognized - based on previous studies - the connection between the now widely used APD and the alterations/deviations of childhood behavior.

\section{Contemporary concepts}

The establishment of the DSM-IV (APA, 2000) followed a tendency to maintain the diagnosis of APD of the previous edition, despite the attempt of the workgroup to simplify the diagnostic criteria of the disorder and include more traditional items, typical of psychopathy, with the intent of increasing congruence and compatibility between the DSMIV and the International Statistical Classification of Diseases and Related Health Problems ICD-10 (World Health Organization, 1990 [WHO]). However, the maintenance of a construct that differs significantly from psychopathy can be observed. This discrepancy became the target of criticism from many researchers, such as the remarks made by Robert D. Hare's group. This group highlighted certain aspects related to the APD description (Hare, Hart, \& Harpur, 1991), such as: the excess of criteria, a great many of them retrospective (patient's previous history, since 15 years of age), and restricting clinicians who apply the manual to using the information provided by the interviewee. This situation is especially problematic with regards to the inclination to lie 
Chart 1

The evolution of concepts and differences in diagnostic criteria for Psychopathy and Antisocial Personality Disorder

\begin{tabular}{|c|c|c|}
\hline Source & Nomenclature & Criteria \\
\hline $\begin{array}{l}\text { David Henderson and } \\
\text { Hervey Cleckley (1939) }\end{array}$ & Psychopathic states & $\begin{array}{l}\text { Superficial charm and "good" intelligence; absence of delusions and } \\
\text { other signs of irrational thinking; absence of "nervousness" or other } \\
\text { signs of psychoneurotic disturbance; unreliability; untruthfulness and } \\
\text { insincerity; lack of remorse or shame; inadequately motivated antisocial } \\
\text { behavior; poor judgment and failure to learn from experience; } \\
\text { pathological egocentricity and incapacity for love; general poverty in } \\
\text { major affective reactions; specific loss of insight; unresponsiveness in } \\
\text { general interpersonal relations; fantastic and uninviting behavior with } \\
\text { drinking and sometimes without; suicide rarely carried out; sex life } \\
\text { impersonal, trivial, and poorly integrated; failure to follow any life plan. }\end{array}$ \\
\hline
\end{tabular}

DSM I (1952) Antisocial reaction (previously classified as "constitutional psychopathic state" and "psychopathic personality")

DSM II (1968) Antisocial personality

DSM III (1980) Antisocial personality disorder
Callous and hedonistic behavior, emotional immaturity, lack of sense of responsibility, lack of judgment, ability to rationalize their behavior.

Incapability of significant loyalty to individuals, groups, or social values; Grossly selfish, callous, irresponsible, impulsive, unable to feel guilt or to learn from experience and punishment, low tolerance to frustration, tendency to blame others and rationalization.

Diagnostic criteria for 301.7 Antisocial Personality Disorder: A) There is a pervasive pattern of disregard for and violation of the rights of others occurring since age 15 years, as indicated by three (or more) of the following: (1) failure to conform to social norms with respect to lawful behaviors as indicated by repeatedly performing acts that are grounds for arrest; (2) deceitfulness, as indicated by repeated lying, use of aliases, or conning others for personal profit or pleasure; (3) impulsivity or failure to plan ahead; (4) irritability and aggressiveness, as indicated by repeated physical fights or assaults; (5) reckless disregard for safety of self or others; (6) consistent irresponsibility, as indicated by repeated failure to sustain consistent work behavior or honor financial obligations; (7) lack of remorse, as indicated by being indifferent to or rationalizing having hurt, mistreated, or stolen from another. B) The individual is at least age 18 years. C) There is evidence of Conduct Disorder with onset before age 15 years. D) The occurrence of antisocial behavior is not exclusively during the course of Schizophrenia or a Manic Episode. and to deny reality, characteristics that are usual in such clinical cases. In addition, still regarding the APD concept, a greater presence of behavioral rather than interpersonal or affective symptoms has been observed. Of the seven criteria included in the " $A$ " criterion of the disorder, only the seventh criterion refers to the affective outcome and rather than the behavioral ones.

According to Hare et al. 1991, by prioritizing such symptomatology, the DSM-IV presumes that personality traits are difficult to compare. Therefore they started using the simpler approach of measuring behaviors which typify a disorder rather than being based on the reasons why they occur. Through the broader use of the instrument or construct reliability index, it was observed that by prioritizing behavioral issues a detachment from the clinical concept of psychopathy is promoted, within which statements about the affective and interpersonal processes have always had an important role. A second criticism of the APD criteria refers to the fact that they represent a significant rupture with tradition and with the clinical practice (Cleckley, 1976), as well as with the previous versions of the DSM (APA, 1952) and with the international diagnosis nomenclature ICD-10 (WHO, 1990). Specifically, the DSM-IV excludes, or at least 
does not explicitly include, characteristics such as selfishness, egocentrism, manipulation, and lack of empathy, amongst others, commonly and historically associated with psychopathy. While the discussions regarding the compatibility between psychopathy and the diagnostic manuals continue, there is a considerable increase in the number of studies debating the construct, independent of the DSM-IV criteria. Theoretical and clinical interest in psychopathy manifestations is increasing, as well as interest in its measurement as described by Cleckley.

The main aim of this study is to conduct a critical review on the evaluation of psychopathic traits in adolescence, emphasizing the distinction between psychopathy, as a clinical construct, and the conduct disorders and APD. In order to elucidate this distinction, the relationship between a phenomenological approach and the description of the behaviors is discussed.

\section{Method}

A systematic online review of literature was conducted using the MedLine database and the descriptors adolescent, antisocial personality disorder, and personality assessment. Primarily 59 articles were recovered, which was reduced to 29 after applying the following inclusion criteria: original articles that involved studies with male individuals, from adolescence until 44 years of age (criteria from MedLine), and articles published in French, English, Spanish, German and Portuguese. The age definition was based on the premise that it is important to comprehend the psychopathic manifestation in the early stages of childhood, adolescence and the beginning of adulthood. The search period was from 1968 (with the introduction of the term APD), to March 2011. The descriptor "psychopathy" is not contained in several databases (amongst them MedLine), although it was the term the authors would have preferred to use. Therefore, the option for "Antisocial Personality Disorder" was the most adequate, given that the chosen database suggests this keyword as a descriptor for 240 psychopathy.

\section{Results and Discussion}

Regarding the 29 papers that were recovered, an initial statement regarding the establishment of the "psychopathy" diagnosis can be made. In some works dated from the beginning of the nineties (1990s) different terms were still used to describe diagnoses that consider the manifestation of violent behavior a personality trait. In the most recent works (after the year 2000), the term "psychopathy" seems to be more used to describe such cases. This change may be attributed, in part, to the impact that the Hare Psychopathy Checklist - Revised (PCL-R) had within the scientific community, establishing itself, over the years, as a reliable instrument that proposes to investigate the construct "psychopathy" as initially suggested by Cleckley (Cleckley, 1976). Therefore, while some older articles used the term psychopathy, based on the initial editions of the DSM (Hawk \& Peterson, 1974), later articles on the evaluation of violence in adolescence use terms such as "antisocial behavior" (Bukowski, Ferber-Goff, \& Newcomb, 1990) or "antisocial traits" (Patterson, 1993), now under the direct influence of the DSM III and IV. After many years and due mainly to research performed with the PCL-R the term "psychopathy" was again referred to in the literature, being easily found in recent studies. The Hawk and Peterson (1974) study, applied the Minnesota Multiphasic Personality Inventory (MMPI) to evaluate whether transgressive behavior associated to psychopathy in the scale is only related to the transgressive behavior itself (without necessarily being connected to psychopathy). Such concerns show the previously described distinction of violent behavior from an isolated point of view, rather than the one associated with affective and interpersonal alterations, i.e., characteristics of psychopathy. The MMPI-2 is a scale that has been frequently used in other situations with similar purposes.

In a recent study (Sellbom, Ben-Porath, \& Stafford, 2007), the MMPI-2 was the instrument chosen to assess transgressive behavior associated with psychopathy in a forensic context. Its restructured clinical scales were separately evaluated to verify which would present the highest correlation 
to psychopathy as presented in the Psychopathy Checklist, Screening Version (PCL-SV) (Hart, Cox, \& Hare, 1995). According to the authors, the Restructured Clinical Scale 4 (RC4) is the clinical scale which presents the highest convergent validity with the PCL-SV and with the behavioral criteria associated with the psychopathy construct. The Clinical Scale 4, that originated the RC4, does not seem to be directly associated to psychopathy, as it measures only transgressive behavior in general. The core symptoms of psychopathy, such as superficial affect, lack of empathy or regret, and lack of fear, are minimally related to this scale, which is the reason for the low clinical proximity. Similarly, general scales that assess personality traits are used in an attempt to differentiate adolescents with psychopathic traits from those without, however, an increase in the use of psychopathy specific instruments can be observed. In the studies investigated, in addition to the MMPI, references to the 16 Personality Factor Test (16PF) were found in a study that evaluated the capacity to deceive or trick the interviewer in a sample of male prisoners (Seibel, Wallbrown, Reuter, \& Barnett, 1990). Because of this characteristic, the manipulation (or a tendency to deceive, trick, and lie) present in psychopathy is one of the greatest biases in instrument elaborations. Therefore, it is necessary to predict such situation in a systematic way. This is one of the reasons why self-reported instruments are not indicated when evaluating a population containing individuals with psychopathy traits (Hare, 2003).

The use of the EPQ-Junior (Eysenck Personality Questionaire - Junior) is highlight in a Portuguese study (Fonseca \& Yule, 1995) which showed no differences in extroversion, neuroticism and psychoticism in transgressive adolescents when compared to non-transgressive adolescents (supposedly the transgressors would score higher in these items). Some studies do not specify the instrument used. The evaluation was performed considering a pattern or a type of behavior, and by observing whether this pattern is maintained or is modified over time (Graybil \& Blackwood, 1996; Patterson, 1993). The comparison between the ways of evaluating characteristics of violence was again discussed (Graybill \& Blackwood, 1996) and compared through the scores for behavior, selfreported instruments and projective tests. In this particular study, the projective tests were more able to predict violent behavior, with up to 5 years of antecedence. In a study performed by Miller and Lynam (2003), the authors evaluated psychopathy through a model of five personality factors, namely the "Big Five Model". The individuals who were closest to the construct of psychopathy, according to the Big Five Model, showed more aggressivity in laboratory controlled tasks, especially those involving immediate gratification.

After the establishment of the scale and the acceptance of the scientific community to reconsider the construct originally proposed by Cleckley, the PCL-R became the most utilized instrument to phenomenologically assess the criteria of the disorder. Furthermore, it was positioned as the exemplary model for the evaluation of psychopathy and as a parameter for validation of new scales (Kosson, Steuerwald, Forth, \& Kirkhart, 1997). This influence is so great that few studies on the subject, after the year 2000, do not involve an instrument of the PCL family. A possible explanation for this influence is the fact that the PCL-R aims to compile items that contemplate the clinically and historically associated manifestation of psychopathy. The items which compose the PCL-R represent an attempt to systematize and guide the research for the symptomatology originally described by Cleckley (1976) (case 1). In addition, the PCL-R considers affective questions that are little explored in other diagnostic instruments. Initially divided into two factors (Hare et al., 1991), the items described in factor 2 are mostly behavioral and similar to the APD in its current form. The items of factor 1 refer to affective and interpersonal issues that no longer appear in the manuals and represent the theoretical and clinic influence. By considering clinical aspects and research on the concept of the construct, the PCL-R has become the most relevant instrument to help in the evaluation of individuals with psychopathic traits at the present time. 
One of the variations of the PCL-R is the PCLSV (Hart et al., 1995) that corresponds to a reduced version with the purpose of obtaining a more rapid assessment, in a screening situation for example. In one study (Rogers et al., 2000) the authors used this instrument in three distinct forensic contexts (incarcerated males, incarcerated adolescents, and incarcerated females), finding strong evidenced for the construct validity, as well as for the capacity of predicting aggression subtypes in specific populations. Regarding the adolescent evaluation, the PCL-R was adapted from the Psychopathy Checklist - Youth Version (PCL-YV) (Forth, Kosson, $\&$ Hare, 2003). Recently adapted to the Brazilian Portuguese language by Gauer, Vasconcellos, \& Werlang (2006), the instrument covers items that consider the particularities of regular adolescent development. For example, juvenile delinquency is investigated as the involvement in criminal behavior of the highest gravity. The marital relationship is not investigated in the version for adolescents; however, interpersonal relationship instability is assessed. The difficulty for the adolescent to establish long term goals in life is also assessed by investigating their life plans, In addition, the semistructured interview that follows the application of the instrument contemplates some specific areas, such as history of adjustment in the school and professional environment, professional goals, drug use, attitude in the presence or absence of others, interpersonal relationships, and antisocial behaviors in childhood and adolescence. Studies involving the use of the PCL-YV have revealed higher scores in incarcerated adolescents and in adolescents that present a high incidence of antisocial behaviors, as well as alcohol and drug abuse (Kosson, Cyterski, Neumann, Steuerwald, \& Walker-Mathews, 2002). Some studies aimed to correlate substances use/ abuse in adolescence with the PCL-R scores (McDermott et al., 2000), using samples of adolescents without a history of legal problems. However, up to now the results presented have been debatable, indicating a higher predictive capacity when the interaction between factors 1 and 2 is 242 separately evaluated.
The Psychopathy Checklist-Youth Version instruction manual describes 19 studies in three different countries, compiling a total sample of 2,438 adolescents. According to the authors, the data from these studies revealed a good diagnostic capacity of the instrument (Forth, Kosson, \& Hare, 2003). The reliability studies of the PCL-YV have contemplated samples of institutionalized adolescents, clinical samples, and samples from the general community. However, of the 19 samples referred to in the manual, 11 were performed with institutionalized adolescents (Forth et al., 2003). A more recent epidemiological data study using the PCL-YV was conducted in Germany (Sevecke, Lehmkuhl, \& Krischer, 2011). The authors suggest a closer investigation of the two core personality dimensions of psychopathy, the age-typical adolescent and the antisocial behavior dimensions, as they can inflate the total PCL-YV score and at the same time present no increased scores in the psychopathy core dimensions. The instrument showed varying rates of prevalence when it was administered with a forensic, clinical and community sample of boys and girls and further analyzed based on three different concepts of psychopathy. However, a high prevalence of psychopathic dimensions was indicated in boys of all the samples.

A systematic review in the literature demonstrates a great demand for instruments and methods capable of predicting violent behavior. In relation to adolescents, this demand is even greater, as during this life period it is also debatable whether intervening measures can represent greater success in the alteration of clinical outcomes (in this case, an adolescent who does or does not carry out violence). It was therefore observed that the majority of recent works discuss the predictive capacity of the instruments and tests. In an article that investigated the influence of biological markers on aggressive behavior (Osterlaan, Geurts, Knol, \& Sergeant, 2005), A low concentration of saliva cortisol was found in children (from 6 to 12 years old) with a history of reports from their teachers of symptoms that are compatible with conduct disorders. In addition to the alterations in the autonomic system, frequently associated with 
violent behavior, other ways to predict violence through biological markers have been discussed. However, the assessment of personality traits still seems to be one of the main instruments to predict violent behavior.

The development of an instrument capable of predicting violence, repeated transgressive acts, or recurrent problems with the legal system, was not the main aim behind the PCL-YV. Nevertheless, because it measures psychopathy traits, it is one of the most researched instruments in this context, by virtue of the association of psychopathy with repeated violent acts and persistent antisocial behavior. This fact is reflected in studies on affective traits, such as superficial affection, and criminal recurrence (Essaau, Sasagawa, \& Frick, 2006), as well as the development of parallel and specific scales to measure the risk of a new event in recurrent aggressors, such as the Inventory of Offender Risk, Needs and Strengths (IORNS). This scale was utilized in a recent work (Miller, 2006) to investigate which would be the best outcome for an aggressor on parole, as well as to evaluate reliability and initial validation.

Some criticism is made regarding the predictive power of the PCL-R, the PCL-YV, and their derivatives, with the argument that many researches were unable to find a strong capacity to predict new violent events. In at least one longitudinal study, contemplating a sequence of 10 years and covering 75 male adolescents with an mean age of 16 (Edens \& Cahill, 2007), it was not possible to correlate the PCL-YV with a fresh prosecution for violence or other illegal acts. One of the criticisms of this type of study is that the outcome fresh prosecution may represent a potential research bias, due to the fact that psychopaths frequently learn to avoid fresh contacts with the law, finding new ways to remain transgressors.

Another aspect to be considered is that the capacity for predicting recurrence through the PCL$R$, presents a greater association of new violent acts when only considering factor 2 (behavioral), consequently becoming a construct once again very similar to the APD. A meta-analysis found that the relationship with violence is much higher considering factor 2 rather than the factor 1 (Walters, 2003). These findings suggest that factor 1 is not as relevant to predict new violent acts. The PCL-YV is divided into 4 factors and has also been the target of studies regarding the predictive capacity of each specific factor. (Vitacco, Neumann, Caldwell, Leistico, \& Van Rybroek, 2006). The dichotomy between factors ends up damaging the understanding and the applicability of the construct, which is more dimensional than categorical. When the interaction between factors is analyzed (rather than each one separately), new conclusions are reached. When the interaction between both factors is considered, some data show that factor 2 is a weaker predictor of violent behavior when the rates are lower in factor 1 (Walsh \& Kosson, 2008). It can be inferred that the capacity for empathy or an affective response may be predictors in individuals with high levels of antisocial impulsivity. Factor 2 alone can help to discriminate individuals who are involved with violence from those that are not; the interaction between factors though, can differentiate those who commit violent acts with higher or lower frequency, as well as the characteristics of such acts.

Kennealy, Skeem, Walters, and Camp (2010) contributed in a valuable manner to the present discussion. They studied the interaction between the PCL-R Social Deviance and InterpersonalAffective scales of psychopathy in order to predict violence beyond the individual capacity of each scale by itself. Their results showed that the Social Deviance scale alone was a better predictor than the Interpersonal-Affective scale, and that these two scales did not interact in order to increase the predictive capacity. The findings of these researchers are of great importance for the assessment and predictability of violence, having fundamental practical implications. According to this study, core interpersonal-affective traits of psychopathy would not increase the risk of violence among individuals with a history of misbehavior. This fact alone could bring theoretical implications to the discussion of psychopathy concepts.

It is important to emphasize some special situations: in a study performed in a high security 
hospital (Morrissey, Mooney, Hogue, Lindsay, \& Taylor, 2007), individuals convicted of different crimes and with intellectual disabilities had their scores in the PCL-R compared to the HCR-20, a scale designed to evaluate the risk of violence. Both scales showed great capacity of assessing the favorable evolution (or not) of the treatment and a consequent change in the incarceration regime (to moderate security). These results showed that the instruments may also have great relevance regarding the type of intervention, course and prognosis of a treatment even in populations not commonly associated with psychopathy, but with violent behavior. Regarding the specific types of crime, few researches try to elucidate or correlate certain pattern to a personality type or psychopathic trait manifestation. Some studies with sexual aggressors, however, showed some association with the PCL-R scores. In a study with undergraduate students (Kosson, Kelly, \& White, 1997), the items of factor 1 related to the use of physical force in sexual aggression, while those of factor 2 related to the use of talking or persuasion in order to engage in sexual activities. In another study, higher scores in sexual aggressors correlated positively with the rape of fertile aged women and negatively with pedophiles and child abusers (Harris, Rice, Hilton, Lalumiére, \& Quinsey, 2007). The same study suggested a Darwinian view associating psychopathic conduct with early, coercive and frequent sex, intending reproduction. Pedophiles, therefore, would not necessarily be psychopaths. It concludes that psychopathy is a viable, and not pathological, characteristic of human beings in a certain moment of evolution.

Although currently the PCL-R and the instruments derived from it, such as the PCL-YV, are the most used by researchers and clinicians around the world, some authors show some uncertainty regarding the construct of psychopathy developed by Hare and colleagues. For example, Skeem \& Cooke (2010) asserted that Hare and Neumann considered criminality to be an essential component of the psychopathy construct. To these authors unfortunately, a side effect of this interest has been conceptual confusion and, in particular,

244 the result is the confusion of measures with constructs. Indeed, the field is in danger of equating the PCL-R with the theoretical construct of psychopathy. A key point in the debate is whether criminal behavior is a core component, or a mere downstream correlate, of psychopathy. The authors present conceptual directions for resolving this debate. They consider the factor analysis of the PCL$R$ items in a theoretical vacuum that cannot reveal the essence of psychopathy. Another aspect considered is a myth about the PCL-R and its relationship with violence, which must be examined to avoid the view that psychopathy is merely a violent variant of an antisocial personality disorder.

A formal, interactive process between theory development and empirical validation must be adopted. Fundamentally, constructs and measures must be recognized as separate entities, with neither of them reified. Such disagreements encouraged Cooke to develop a further instrument, the Comprehensive Assessment of the Psychopathic Personality (CAPP), which was validated in many countries, such as Germany and Portugal. Recently, the scientific community has considered this subject as an important and relevant matter for debate. The concept that was developed for years by authors such as Cleckley was completely rejected by the American Psychiatric Association. Now, as the construct has been reconsidered, some authors have begun to question its recent reviews (Skeem \& Cooke, 2010). The attempt to systematize psychopathy, through structured interviews or evaluation instruments, based on previous descriptions of the construct, has proved to be a difficult task. However, its acceptance and relevance among the scientific community has recently increased. As with all reviewed or reconstructed diagnosis parameters, psychopathy still needs further studies that can unanimously agree on a way of measuring the phenomenon. However, among the available ways of assessing psychopathic behavior, the Hare Psychopathy Checklist (PCL-R) and its derivatives seem to be of unique importance, specifically the version for adolescents (PCL-YV). Even though this is a new instrument, it has been of great help in studies and in the construction of a body of possible etiological aspects of psychopathy 
in adolescents. In conclusion, the understanding of psychopathy and its manifestations is relevant not only to perform a proper diagnosis, but, fundamentally, to plan and apply early interventions capable of modifying the natural history of the disorder that currently follows an inexorable path. Instruments and interventions which focus on adolescence are of special importance, as this life stage represents a period of hopeful positive changes, which could alter the outcome of a supposedly already told story.

\section{References}

American Psychiatric Association. (1952). Diagnostical and Statistical Manual of Mental Disorders (DSM-I). Washington, DC: Author.

American Psychiatric Association. (1968). Diagnostical and Statistical Manual of Mental Disorders (DSMII) (2 ${ }^{\text {nd }}$ ed.). Washington, DC: Author.

American Psychiatric Association. (1980). Diagnostical and Statistical Manual of Mental Disorders (DSM-III) $\left(3^{\text {th }}\right.$ ed). Washington, DC: Author.

American Psychiatric Association. (2000). Diagnostical and Statistical Manual of Mental Disorders (DSM-IV) $\left(4^{\text {th }}\right.$ ed.). Washington, DC: Author.

Black, D. W., \& Larson C. L. (1999). Bad boys, bad men: Confronting antisocial personality disorder. Oxford University Press.

Bukowski, W. M., Ferber Goff, J., \& Newcomb A. F. (1990). The stability and coherence of aggregated and singleitem measure of antisocial behavior. Brazilian Journal of Social Psychology, 29(Pt 2), 171-180.

Cleckley, H. (1976). The mask of sanity ( $5^{\text {th }}$ ed.) St. Louis, MO: Mosby.

Edens, J. F., \& Cahill, M. A. (2007). Psychopathy in adolescence and criminal recidivism in young adulthood: Longitudinal results from a multiethnic sample of youthful offenders. Assessment, 14(1), 57-64.

Essaau, C. A., Sasagawa, S., \& Frick, P. J. (2006). Callousunemotional traits in a community sample of adolescents. Assessment, 13(4), 454-469.

Fonseca, A. C., \& Yule, W. (1995). Personality and antisocial behavior in children and adolescents: An enquiry into Eysenck's and Gray's theories. Journal of Abnormal Child Psychology, 23(6), 767-781.

Forth, A. E., Kosson, D. S., \& Hare, R. D. (2003). Hare psychopathy youth version manual. Toronto: MultiHealth Systems.

Forth, A. E., Kosson, D. S., \& Hare, R. D. (2003). Inventário de psicopatia de Hare: versão jovens (PCL:YVTM): manual técnico (Versão Brasileira). Toronto: MultiHealth Systems.

Gauer, G. J. C., Vasconcellos, S. J. L., \& Werlang, B. (2006). Inventário de psicopatia de Hare: versão jovens (PCL:YVTM) (Versão Brasileira). Toronto: Multi-Health Systems.

Graybill, D., \& Blackwood, A. (1996). Prediction of adolescent aggression by childhood personality measures: A comparison of projective procedures, self report tests, and behavior ratings. Journal of Clinical Psychology, 52(1), 61-66.

Hare, R. D. (2003). The Hare psychopathy checklist: Revised ( $2^{\text {nd }}$ ed.). Toronto: Multi Health Systems.

Hare, R. D., Hart, S. D., \& Harpur, T. J. (1991). Psychopathy and the DSM-IV criteria for antisocial personality disorder. Journal of Abnormal Psychology, 100(3), 391-398.

Harris, G. T., Rice, M. E., Hilton, N. Z., Lalumiére, M. L., \& Quinsey, V. L. (2007). Coercive and precocious sexuality as a fundamental aspect of psychopathy read. Journal of Personality Disorders, 21(1), 1-27.

Hart, S. D., Cox, D. N., \& Hare, R. D. (1995). Manual for the Psychopathy Checklist: Screening version (PCL SV). Toronto: Multi-Health Systems.

Hawk, S. S., \& Peterson, R. A. (1974). Do MMPI psychopathic deviancy scores reflect psychopathic deviancy or just deviancy? Journal of Personality Assessment, 38(4), 177-182.

Kennealy, P. J., Skeem, J. L., Walters, G. D., \& Camp, J. (2010). Do Core interpersonal and affective traits of PCL-R psychopathy interact with antisocial behavior and disinhibition to predict violence? Psychological Assessment, 22(3), 569-580.

Kosson, D. S., Kelly, J. C., \& White, J. W. (1997). Psychopathic related traits predict self-reported sexual aggression among college men. Journal of Interpersonal Violence, 12(2), 241-254.

Kosson, D. S., Steuerwald, B. L., Forth, A. E., \& Kirkhart, K. J. (1997). A new method for assessing interpersonal behavior of psychopathic individuals: Preliminary validation studies. Psychological Assessment, 9(2), 89-101.

Kosson, D. S., Cyterski, T. D., Neumann, C. S., Steuerwald, B. L., \& Walker-Matthews, S. W. (2002). The reliability and validity of the Psychopathy Checklist: Youth version (PCL:YV) in no incarcerated adolescent males. Psychological Assessment, 14(1), 97-109.

McDermott, P. A., Alterman, A. I., Cacciola, J. S., Rutherford, M. J., Newman, J. P., \& Mulholland, E. M. (2000). Generality of psychopathy checklist: Revised factors over prisoners and substance-dependent patients. Journal of Consulting and Clinical Psychology, 68(1), 181-186.

Miller, H. A. (2006). A dynamic assessment of offender risk, needs and strengths in a sample of pre-release 
general offenders. Behavioral Sciences \& the Law, 24(6), 767-782.

Miller, J. D., \& Lynam, D. R. (2003). Psychopathy and the five factor model of personality: A replication and extension. Journal of Personality Assessment, 81(2), 168-178.

Morrissey, C., Mooney, P., Hogue, T. E., Lindsay, W. R., \& Taylor, J. L. (2007). Predictive Validity of the PCL-R for offenders with intellectual disability in a high security hospital: Treatment progress. Journal of Intellectual \& Developmental Disability, 32(2), 125-133.

Osterlaan, J., Geurts, H. M., Knol, D. L., \& Sergeant, J. A. (2005). Low basal salivary cortisol is associated with teacher-reported symptoms of conduct disorder. Psychiatry Research, 134(1), 1-10.

Patterson, G. R. (1993). Orderly change in a stable world: The antisocial trait as a chimera. Journal of Consulting and Clinical Psychology, 61(6), 911-999.

Rogers, R., Salekin, R. T., Hill, C., Sewell, K. W., Murdock, M. E., \& Neumann, C. S. (2000). The psychopathy checklist: Screening version: An examination of criteria and subcriteria in three forensic samples. Assessment, 7(1), 1-15.

Seibel, H. P., Wallbrown, F. H., Reuter E. K., \& Barnett, R. W. (1990). Further evidence concerning motivational distortion on the sixteen personality factor primaries by male felons. Journal of Personality Assessment, 55(1-2), 367-375.

Sellbom, M., Ben-Porath, Y. S., \& Stafford, K. P. (2007). A comparison of MMPI-2 measures of psychopathic deviance in a forensic setting. Psychological Assessment, 19(4), 430-436.

Sevecke, K., Lehmkuhl, G., \& Krischer, M. K. (2011). Epidmiological data on personality dimensions in the psychopathy of adolescent boys and girls: Results of Cologne GAP study. Z Kinder Jugendpsychiatr Psychother, 39(1), 9-20.

Skeem, J. L., \& Cooke, D. J. (2010). Is criminal behavior a central component of psychopathy? Conceptual directions for resolving the debate. Psychological Assessment, 22(2), 433-445.

Vitacco, M. J., Neumann, C. S., Caldwell, M. F., Leistico, A. M., \& Van Rybroek, G. J. (2006). Testing factor models of the psychopathy checklist: Youth version and their association with instrumental aggression. Journal of Personality Assessment, 87(1), 454-469.

Walsh, Z., \& Kosson, D. S. (2008). Psychopathy and Violence: The importance of factor level interactions. Psychological Assessment, 20(2), 114-120.

Walters, G. D. (2003). Predicting institutional adjustment and recidivism with the psychopathy checklist Factor Scores: A meta analysis. Law and Human Behavior, 27(5), 541-558.

World Health Organization. (1990). International classification of diseases and related health problems (10 ed.). Geneva: Author.

Received on: 4/23/2012

Final version on: 5/14/2012

Approved on: 6/11/2012 